\title{
We collaborate with everyone, but with some more than others: evidence of stakeholder collaboration among internal security professional higher education institutions
}

\author{
Anne Valk ${ }^{*}(0)$ and Mairit Kratovitš
}

\section{${ }^{*}$ Correspondence:}

anne.valk@sisekaitse.ee

Centre of Law and Social

Sciences, Estonian Academy

of Security Sciences, Kase 61,

12120 Tallinn, Estonia

\begin{abstract}
The aim of this article is to identify the main stakeholders of institutions of professional higher education in the field of internal security in selected countries, and the most important collaboration practices, and the factors that affect collaboration. Within the framework of a qualitative phenomenographic study, interviews were conducted with representatives of Estonian, German, Finnish, and Norwegian institutions of professional education in the field of internal security. The results showed that institutions of professional higher education differ from traditional universities in prioritizing their main stakeholders, putting employers first, and not students. In addition, the ministries under whose government they operate, and other higher education institutions were named as the main stakeholders. Collaboration with stakeholders is mostly based on common interests and personal relationships (e.g., mediation, networking, joint reputation building, collaboration councils), on some kind of formal basis (e.g., feedback system, collaboration councils) or subordination (e.g., execution of orders and instructions, trading). The aspects most influencing collaboration were considered to be the aspects related to trust and professionalism, and in particular informal collaboration was valued. The results of this study enabled the author to supplement a framework from a previous study, which originally described the theoretical collaboration of the stakeholders of an institution of higher education in the field of internal security; this was supplemented by adding the dimension of collaboration diversity.
\end{abstract}

Keywords: Professional higher education, Internal security, Stakeholder collaboration, Collaboration forms, Phenomenography

\section{Introduction}

The European binary higher education system offers various opportunities for the acquisition of professional higher education in addition to academic education. The term "professional higher education" is a multifaceted phenomenon, and there is no consensus among countries regarding its name and content. Despite conceptual and

(c) The Author(s) 2021. This article is licensed under a Creative Commons Attribution 4.0 International License, which permits use, sharing adaptation, distribution and reproduction in any medium or format, as long as you give appropriate credit to the original author(s) and the source, provide a link to the Creative Commons licence, and indicate if changes were made. The images or other third party material in this article are included in the article's Creative Commons licence, unless indicated otherwise in a credit line to the material. If material is not included in the article's Creative Commons licence and your intended use is not permitted by statutory regulation or exceeds the permitted use, you will need to obtain permission directly from the copyright holder. To view a copy of this licence, visit http://creativeco mmons.org/licenses/by/4.0/. 
programmatic differences, the common feature of the institutions operating in fields of professional higher education is that, in addition to general competencies, the practical needs of the labor market are catered for. In this article, we discuss professional higher education, which covers professional qualifications at European Qualifications Framework (EQF) levels 5 to 8 (European Union 2018: 18-19) and which includes short cycle (Diploma Studies), professional bachelor and master degrees at these levels (Ulicna et al. 2016: 1). This article focuses on professional higher education institutions providing internal security education in countries, most of which have been leaders in the development of professional higher education in Europe. Germany has been described as an "apprenticeship country," characterized by the strong involvement of non-governmental stakeholders in the development of the vocational education and training system and strong interest among employers in being involved and providing learning opportunities and the practical experience needed to acquire skills (Deissinger 2000, 2015; Deissinger and Gonon 2016). Employers also play an important role in the Finnish higher education system, where professional higher education institutions focus mainly on regional development (Kettunen 2015). In Norway, on the other hand, a greater merging of professionally oriented regional colleges took place in 1994, which resulted in the emergence of 26 national colleges instead of the previous 98 . The share of external and internal stakeholders in the councils of these colleges was also equalized after some time (Musial 2010). The number of colleges has been reduced for now because some of them have merged with universities or have become universities, but professional higher education is still important, and various opportunities are being sought to develop this sector alongside universities (Cedefop 2017: 208-209). Estonian institutions of professional higher education are characterized by sectoral specialization and strong ties with employers, and they have undergone thorough development to become recognized collaboration partners both domestically and internationally. The motivation for the emergence of Estonian professional higher education institutions was the example of Germany and Finland and pressure from local companies that needed competent specialists (Lend et al. 2014: 7-8). All the countries selected for the study have institutions of professional higher education, providing internal security education mainly in the field of the police, but in some countries also in rescue, taxation, customs, border guard, correctional institutions, and others. In Germany, the training of internal security personnel is predominantly federal. For example, each of the 16 federal states in Germany has its own police education institutions under the supervision of the state's ministries of the interior. As there are 16 different police laws, the designations and legal status of the institutions vary (Feltes et al. 2013). There are three levels of police higher education provided, from which operative service training takes place in police academies, 'elevated' service is carried out at a university of applied sciences (bachelor of arts degree), and senior-level (master degree) education takes place at one university-the German Police University in Munster (Dekanoidze and Khelashvili 2018, p. 106), whose structure involves both the national level and the German federal states (Feltes et al. 2013). Through the internet search engine Google, you can also find a number of rescue and customs personnel training universities of applied sciences in the various federal states of Germany. In Finland, specialist fields related to internal security are taught in public professional higher education institutions. For example, professional higher education institutions specializing 
in the police service, border guard service, and rescue service are in the administrative area of the Ministry of the Interior (Ministry of the Interior Finland Homepage). At the same time, it is also possible to acquire broader-based education in the field of internal security (safety, security and risk management) at a higher education institution under the Ministry of Education and Culture, where you can also study in other fields (nursing, social services, etc.) (Study in Finland Homepage). In Norway, there is a university specializing in the police service under the Ministry of Justice and Public Security, where it is possible to study for both bachelor and master degrees, and an academy for correctional officers under the same ministry, where a bachelor degree can be obtained. It is also possible to obtain a master degree in fire safety at a professional higher education institution under the Ministry of Education (OECD 2018: 63). In Estonia, education in the field of internal security is provided by one professional higher education institution under the administration of the Ministry of the Interior, where it is possible to study in the fields of police and border guard, rescue, taxation, customs, and corrections. Master studies in internal security are also offered. It is a unique institutionally accredited professional higher education institution in Europe, which concentrates on diverse competencies in the field of internal security (Dekanoidze and Khelashvili 2018, p. 76-77;79;81).

In view of the above, it can be concluded that institutions of professional higher education could have an increased interest in developing informed and targeted collaboration with internal and external stakeholders due to their focus on practical training. Therefore, this article aims to explore the content of such collaboration based on European countries successfully providing professional higher education. Furthermore, the article focuses on institutions of professional higher education in the field of internal security because this helps form the basis of the people's sense of security and because this is, to the author's knowledge, a largely unexplored field of education. The research seeks to answer the following question:

Who are the main stakeholders of the institutions of professional higher education operating in the field of internal security, and what are the nature and main influencers of the cooperation with them?

In order to answer this question, the study aims to identify:

a. The main stakeholders of institutions of professional higher education in the field of internal security in the selected countries;

b. the most important collaboration practices;

c. the factors that affect cooperation.

It is a descriptive study that aims to describe and classify the properties associated with a phenomenon (Sandelowski 2000). The main outcome of the study will involve highlighting the links between stakeholder theory and the practice of collaboration with the stakeholders of institutions of professional higher education in terms of the above and create a descriptive framework for collaboration between institutions of professional higher education and their stakeholders, which further research can test in areas other than internal security. The initial perception of the authors is that in the main, the collaboration of public institutions of professional higher education could be viewed on a similar basis because the basic processes are similar from one institution to the next. 
The first part of the article provides a brief overview of the foundations of stakeholder theory and discusses its possible limitations. It also focuses on some stakeholder surveys conducted in institutions of higher education, the diversity of forms of collaboration, and the factors influencing collaboration. The second part of the article explains the design and implementation of the phenomenographic study, and the third part presents the results of the study. This is followed by a discussion of the results and a descriptive framework of the stakeholders of institutions of professional higher education in the field of internal security and of the collaboration conducted between them. The final part presents a summary of the conclusions from the study.

\section{Basis and criticism of stakeholder theory}

Edward Freeman (2010: 25), according to whom a stakeholder can be "any group or individual who can be affected or is affected by the achievement of the firm's objectives," can be considered the founder of stakeholder theory. Stakeholders are broadly classified as primary and secondary (Mitchell et al. 1997; Clarkson 1995), which means that some stakeholders are more important to the organization because of their greater impact on it. The first, more in-depth discussion of stakeholder classification and prioritization is also based on the assumption that stakeholder salience is related to their potential impact on an organization, which is expressed through three factors: power, legitimacy, and urgency (Mitchell et al. 1997). Based on these factors, Mitchell et al. (1997) developed a model that distinguished between latent (dormant, discretionary, demanding), expectant (dominant, dangerous, dependent) and definitive stakeholders, from which latent stakeholders have one salience factor (e.g., urgency), expectant stakeholders have two (e.g., urgency and legitimacy) and definitive stakeholders possess all three factors (urgency, legitimacy, and power).

It can be seen that the original definition of a stakeholder is general enough and gives researchers aspiring to further develop the theory a lot of room for maneuvering, as evidenced by the fact that there have been various tensions and criticisms about stakeholder theory since its inception. It has been criticized both for the lack of a normative context and the consequent lack of practicality in using it in strategic management and problem-solving (Goodpaster 1991; Sternberg 1997; Hasnas 1998; Key 1999; Jensen 2001; Orts and Strudler 2002; Friedman and Miles 2002; Marcoux 2003; Parent and Deephouse 2007; Mainardes et al. 2010, 2011), as well as the lack of a sufficient scientific basis (Key 1999). According to the founders of the theory, however, the aim of stakeholder theory is not to provide solutions to all the problems related to stakeholders but to describe how to involve stakeholders and create value for them. They consider the interactions between the participants in the process of creating value to be the distinguishing elements of the theory (Freeman et al. 2018). As it is a descriptive model, it is also acknowledged that it can only have indirect normative content that guides the choice of variables to be used (Wood et al. 2018). Therefore, it can be concluded that expectations of stakeholder theory are of a rather practical nature, while the theory can never provide everything that practice needs, and accordingly, different further developments are natural.

For example, Parent and Deephouse (2007) argued that the model could be narrower, as their study showed that most stakeholders were in practice in the definitive, 
dominant, and dormant areas, and there was also a management-level effect on stakeholder classification. Some different views of the top and middle managers in the classification of interest groups have also been mentioned by Mainardes et al. (2010), who also question the binary nature of the attributes of the model by Mitchell et al. (1997). It is true, however, that there is probably no equal interaction with more and less powerful stakeholders. Even if the stakeholder possesses all three salience characteristics (power, legitimacy, and urgency), but to a small extent, then it is probably not a significant stakeholder. Based on this, Mainardes et al. (2012) propose their own model of six types of stakeholders while also introducing the mutual influence of the parties and the indicators of strength compared to the previous model. The original model has also been further developed by Friedman and Miles (2002), who consider the under-utilization of the organization/stakeholder relationship to be a weakness of stakeholder theory and see the need to supplement the theory with two distinctions: whether the relationship is based on compatible or incompatible interests in terms of ideas and implementation, and whether the relationship is necessary (internal or logically linked) or conditional (external, not fully linked).

In view of the above, it is possible to argue that the management of stakeholders should first start with an analysis of mutual interests. A comparison of the values of stakeholders with those of oneself as a potential partner (Mampaey and Huisman 2015) is also not insignificant here. One of the disadvantages of stakeholder theory is also that it treats relationships with stakeholders often as separate, while different branches of the theory (e.g., Rowley 1997) treat organizations as parts of a network with complex intertwined relationships (Neville and Menguc 2006).

Therefore, it cannot be assumed that one theory provides answers to all questions related to stakeholder management and that the theory can be put into practice directly in its entirety. Rather, stakeholder theory can be seen here as a possible tool that can be adapted to the circumstances, and various developers have tried to do that from their own point of view. It is also clear that this is not a single theory, but a combination of several different stakeholder theories, which on the one hand, complement each other, and on the other hand, highlight contradictions and thus create a kind of conceptual diversity throughout the research landscape.

\section{Defining and prioritizing stakeholders in an institution of higher education in a changing environment}

Although institutions of higher education have over time been evaluated by various input- and output-based indicators (e.g., alumni success or talent detection and development), a process-oriented approach is also gaining popularity, showing the level and manner of involvement of appropriate stakeholders in the various processes of the institution, including the definition and evaluation of quality (Maguad 2018). Based on a study by Beerkens and Udam (2017), for example, internal stakeholders expect the quality definition and assessment process to be supportive and constructive, and external stakeholders want information about the credibility of the university. The term "stakeholder society" thus refers to two developments in the involvement of external actors in higher education systems: first, their changing role and, second, the increasing responsibility of higher education to the wider public for their actions (de Wit, Verhoeven Wit 
and Verhoeven 2000). The relationship with the environment is, therefore, indispensable on the one hand and mutually beneficial on the other, and organizations must decide to what extent and in what way the interaction should take place. It is clear that an understanding of the complexity of the environment is a prerequisite for the effective management of institutions of higher education, and successful stakeholder management also helps to increase competitive advantage (Maric 2013).

Stakeholder identification and prioritization research has been conducted by several researchers in universities. In most cases, students are mentioned as the first and main stakeholders in these studies (Mainardes et al. 2010; Chapleo and Simms 2010; Slabá 2015). The first author of the article was unable to find similar research on the stakeholders of professional higher education institutions, but Catharina Bjørkquist has concluded from her doctoral research that although both universities and institutions of professional higher education are increasingly focused on stakeholder collaboration, they are distinguished by the fact that universities focus more on internal stakeholders, who also have a say in important decisions, whereas institutions of professional higher education are more guided by collaboration with external stakeholders, who also have a significant economic and political impact on them (Bjørkquist 2009, p. 187-189; 195196; 206-208).

In addition, Valk (2014) has created a descriptive framework for the relations between the stakeholders of institutions of professional higher education in the field of internal security, which distinguishes four main components: (1) stakeholders, (2) the nature of the collaboration, (3) forms of collaboration, and (4) factors influencing collaboration. The framework identifies two types of relationships-a mutual interest-based collaboration partnership and a continuous or periodic implementation partnership. The first type involves stakeholders who have rather informal power, and communication is based on mutual interest and trust, while the second type is more dependent on the stakeholders and involves formal collaboration aimed at broadly meeting some kinds of guidelines or goals. Stakeholders were divided into three based on the nature of the relationship:

1. Interdependent stakeholders (administration and employees, suppliers, competitors, communities, donors and international partners), whose salience factors include informal power and legitimacy and who represent mutual interest-based collaboration partnership relations;

2. Dominant stakeholders who have both formal and informal power (governing entities and regulators, clientele, non-governmental regulators) and legitimacy, and who represent implementation partnership-type collaboration relations;

3. Definitive stakeholders who have formal power, legitimacy, and urgency (main regulator-Ministry of the Interior) and who represent implementation partnership-type collaboration relations.

As this is a theoretical framework created on the example of an institution of professional higher education in the field of internal security, it has also been used as the basis for building the study conducted within the framework of this article and analyzing the results. The aim was to test this framework in practice and increase its practical relevance. Based on the general classification of stakeholders into primary and secondary 
(Mitchell et al. 1997; Clarkson 1995), the prerequisite of the study discussed in this article is that addressing all stakeholders is not practical and that it is important to know how institutions of professional higher education actually prioritize stakeholders. It should also be noted that the relationships between an organization and its various stakeholders are dynamic; the power of some stakeholders may change over time and be linked to a specific context so that not all stakeholders are equally important (Podnar and Jancic 2006).

\section{Forms of collaboration with stakeholders and factors influencing collaboration}

Collaboration is mostly seen as a process in which different parties seek solutions that go beyond the individual perspective (Gray 1989, p. 5), where the joint effort is seen as a key prerequisite for achieving short and long-term goals, which would not have been achieved working separately (Gajda 2004) and where it is possible to distinguish certain stages (formation, operation, and liquidation) (Levine and Moreland 2004).

Although the theoretical literature is sometimes characterized by some ambiguity of terms, and concepts such as collaboration, cooperation, coordination, and so on, are discussed as synonymous (O'Leary and Vij 2012), the connections between the concepts are, in fact, quite logical. In the broadest sense, collaboration is interaction, while cooperation is the structure of this interaction that helps to achieve the goal (Panitz 1996). Collaboration relates to "soft" characteristics such as trust, communication, commitment, common goals, information sharing, transparency, and collective identity, and cooperation and coordination, in turn, relate to the organization, control, and the independent performance of work (Hogue 1993; Frey et al. 2006; Schöttle et al. 2014; Greer 2017: 132-133). According to Arnold et al. (2012), cooperation allows for the division of tasks, the result of which must eventually be consolidated into a larger whole; collaboration does not require such specialization, but all members work synchronously at different stages of the project. However, effective collaboration cannot take place without simultaneous cooperation and coordination as integral parts of the collaboration (Peterson, 1991). Logically, it can be concluded that cooperation is a shorter-term activity, while collaboration is a more permanent relationship that has developed as a result of constant practice. The emergence of collaboration is influenced by both the individual characteristics of the agents involved (e.g., inequality and bargaining power) and collective manifestations (e.g., the formation of coalitions and other structures) (Conte and Castelfranchi 1996).

Various sources speak of a form of collaboration between a university and an employer (Caloghirou et al. 2001; Bruneel et al. 2010; Seppo and Roolaht 2012; Melhuish 2017) or a mutually beneficial collaboration between a university, an employer, and society (e.g., Russo et al. 2007; Azman et al. 2018), where the greatest benefit is considered to be the positive effect on the knowledge base of all parties (Caloghirou et al. 2001). The organization's communication with the external environment, including stakeholders, can take place proactively or responsively. Proactive orientation, which essentially means leading stakeholders in their satisfaction (Casablancas 2015: 110) and is related to a much broader involvement of stakeholders (Buysse and Verbeke 2003), seeks to meet the latent needs of stakeholders of which they are not yet aware, while responsive orientation simply seeks to examine and satisfy customer needs by periodically monitoring their 
satisfaction (Narver et al. 2004; Casablancas 2015: 21). In an environment of increasing uncertainty, a combination of the two possible behaviors is needed, as research shows that public universities with a strong responsive and proactive approach perform better in terms of customer satisfaction, reputation, and resource acquisition (Alarcón-delAmo et al. 2016). In order to take a proactive role, it is recommended to inform and "shake" the stakeholders; that is, to bring them out of their comfort zone, to ask them for input, and to develop collaboration in order to achieve satisfaction, which will lead to favorable changes in the operating environment (Sulkowski et al. 2018).

Collaboration is not always without problems, and one should be consciously prepared to deal with potential barriers, which may include differences in goals (Seppo and Roolaht 2012; Bruneel et al. 2010) and in culture (Azman et al. 2018; Schlierer et al. (2012), misunderstandings and remuneration systems (Seppo and Roolaht 2012), different focuses and priorities (Seppo and Roolaht 2012; Azman et al. 2018) and a lack of communication (Bruneel et al. 2010; Seppo and Roolaht 2012). Barriers to collaboration can be a lack of interest as well as a lack of information or a perceived lack of capabilities in the potential partner (Seppo and Roolaht, 2012; Azman et al. 2018). For example, research shows that industry representatives believe that academics are unfamiliar with new knowledge, and therefore there is a lack of confidence in professors (Azman et al. 2018). Stakeholders' interests can also be conflicting, and communication between institutions of higher education and employers can be complicated; for example, due to the different perceptions and wishes of sectoral employers/professions (Haaristo et al. 2015: 35-36).

In order to overcome the barriers to collaboration, institutions of higher education are urged to focus on the greater applicability of the conducted research, the targeted use of research laboratories, and more efficient communication (Seppo and Roolaht 2012). Work should be done consistently to build trust (Azman et al. 2018; Williamson et al. 2016). One way for academics to increase this is to make themselves more accessible and visible, to communicate their research to the general public, and to give presentations in a language and style that the target group can understand (Azman et al. 2018). Trust and respect are also reflected in taking sufficient time with the partner and a positive attitude towards collaboration (Williamson et al. 2016). It has also been found that previous collaborative experience contributes to overcoming barriers (Bruneel et al. 2010) and that organizations should pay equal attention to the institutional, cultural, and linguistic aspects of communicating with stakeholders (Schlierer et al. 2012).

In general, two types of stakeholder management can be distinguished: focusing on the well-being of one's own organization (organization-oriented stakeholder management) or focusing on an issue that affects the organization's relationships with other societal groups and organizations (thematic stakeholder management). The two approaches also complement each other. It has been observed that thematic stakeholder management dominates in multi-stakeholder networks, as the key to this is a discussion that facilitates the resolution of complex problems and challenges in collaboration with stakeholders and for better coping with the numerous and sometimes conflicting demands of stakeholders (Roloff 2008).

In conclusion, it can be said that collaboration with stakeholders is a mutually beneficial activity, and as in any communication, there are pitfalls. It is a great challenge to 
consider your own and your partner's interests at the same time and to keep the relationship sustainable. As the factors most influencing collaboration are related to the internal capacity of the organizations and the mutual trust of the partners, to a large extent, the activities related to the collaboration can be considered a long-term process of building mutual trust.

\section{Method}

In order to identify the main stakeholders, the most important forms and practices of collaboration, and the factors that influence collaboration in the field of internal security, the authors used a phenomenographic research method aimed at describing and analyzing people's experiences (Marton 1981). This offers a perspective based on how the world is perceived and experienced and what people think about the existence of a phenomenon. Phenomenography assumes that each subject sees a phenomenon from a different angle, and it is important to focus on differences in human perceptions and their interpretation, as reality can be perceived or understood relatively (Marton 1981; Barnard et al. 1999; Akerlind 2005, 2008). This study is based on the assumption that each person exposed to stakeholders has their own understanding of stakeholder prioritization and personal experience of working with stakeholders. Generalization in phenomenographic research means that the phenomenon under study has as many properties as possible; in other words, the richness and thoroughness of the descriptions are important (Thorne et al. 2009).

\section{Sample and procedure of the study}

The targeted sample consisted of 11 key individuals dealing with stakeholders in selected institutions of professional higher education from different levels of the organization (Rector, heads of responsible departments, professors). Institutions of professional higher education offering internal security education in four countries (Estonia, Finland, Norway, Germany) were included in the study. The study used targeted maximum variation sampling to map common patterns that emerge from variations and possible uniqueness (Patton 2002: 234-235). This was also combined with the chain sampling principle to find "information-rich key informants" (Patton 2002: 237), so there were several stages in its formation. The first step was to develop initial selection criteria for countries. In order to find the maximum variability among these countries, the selection criteria were set at different sizes of countries (large, medium, small), the different bases for the structure of the system of professional higher education institutions (regional versus national institutions), different management organizations and the existence of central schools in a specific field (police) (Germany and Norway in our sample) as well as offering broader internal security education (Finland and Estonia in our sample). Based on the principles of the qualitative study, the entire population was not mapped, but the next step was to contact one institution of professional higher education where the researchers had personal contacts, explain the content of the study and ask for help in finding institutions of professional higher education in other countries. On obtaining these contacts, schools were selected in the third stage, their external relations departments were contacted and asked for help in finding suitable interviewees dealing with stakeholders and, in the interest of having more diverse material, if possible, would also 
be from different levels or structures (head, teaching unit, administrative unit). The contact persons, in turn, interacted with various units within the organization, resulting in a final sample. This chain principle was used because the researchers were not able to make decisions on the basis of insufficient external information, and it was important that the sample included people who met the set criteria and who work closely with stakeholders in their work practice. In total, one higher education institution from each of three countries (small and medium-sized countries) and two higher education institutions from a large country were included in the sample. In the latter case, different types of schools (an institution of professional higher education and a police academy) were also selected. One of the data collection methods used was semi-structured in-depth interviews with eight people. Three of these interviews were conducted in Estonian on a face-to-face basis, and five interviews in English using the Skype application. In addition, semi-structured paired interviews conducted in English using the Skype application were used for two people, and one person underwent a qualitative written interview in English (Table 1). All subjects were asked the same questions. The use of different data collection methods was due to the fact that attempts to schedule separate interviews with respondents from one country were for a long time unsuccessful, so the solution was to interview two people together and while they were in the same environment. It was not possible to agree on an interview with one of the subjects, but the person was interested in participating in the study and sent his thoughts in the form of a thorough written text and was ready to answer additional questions if necessary. The main idea of this study was to obtain rich, diverse, and various material on the main phenomenon, and all methods allowed this, as the interviewees were asked the same questions and their answers were detailed and thorough in all cases. The aim of the researchers was not to compare different countries, organizations, practices, and experiences but to look for interesting forms of cooperation and possible commonalities arising from the variability. All interviews were recorded and lasted between $50 \mathrm{~min}$ and $1 \mathrm{~h}$ and $46 \mathrm{~min}$. The interviewees received general interview questions in advance, which allowed them to think more thoroughly about their answers. As we sent a request to higher education institutions to participate in the study by e-mail, all of them also wanted to receive basic questions in order to find suitable participants.

Table 1 Survey of interviewees (compiled by the authors)

\begin{tabular}{llll}
\hline Country & Type of interview & Duration of the interview & $\begin{array}{l}\text { Respondent } \\
\text { code }\end{array}$ \\
\hline Estonia & Face-to-face interview & $53 \mathrm{~min}$ & $\mathrm{E} 1$ \\
Estonia & Face-to-face interview & $1 \mathrm{~h} 46 \mathrm{~min}$ & $\mathrm{E} 2$ \\
Estonia & Face-to-face interview & $58 \mathrm{~min}$ & $\mathrm{E} 3$ \\
Finland & Skype interview & $58 \mathrm{~min}$ & $\mathrm{~F} 1$ \\
Finland & Skype interview & $56 \mathrm{~min}$ & $\mathrm{~F} 2$ \\
Norway & Skype interview & $1 \mathrm{~h} 4 \mathrm{~min}$ & $\mathrm{~N} 1$ \\
Norway & Skype interview & $53 \mathrm{~min}$ & $\mathrm{~N} 2$ \\
Norway & Skype interview & $50 \mathrm{~min}$ & $\mathrm{~N} 3$ \\
Germany & Paired interview, Skype & $56 \mathrm{~min}$ & $\mathrm{G} 1$ \\
& Paired interview, Skype & & $\mathrm{G} 2$ \\
Germany & Written answers & - & $\mathrm{G} 0$ \\
\hline
\end{tabular}


The research questions were based on Valk's (2014) theoretical framework of the stakeholders of institutions of professional higher education in the field of internal security and their mutual relations, which distinguishes four main components: stakeholders, nature of collaboration, forms of cooperation, and factors influencing collaboration, resulting in four main blocks of interview questions:

1. Who are the stakeholders, and how can they be distributed?

2. What is the collaboration relationship based on?

3. What are the main forms and principles of collaboration?

4. What are the factors that affect collaboration?

Each block contained helpful questions that specified the interviewees' answers to the main topic. As it was a qualitative semi-structured interview, the previously sent questions served as the general framework, and the interviewees were allowed to talk freely about collaboration (Yin, 2011: 136-137).

The interviews were transcribed, and the texts encoded using NVivo11. The analysis method used was conventional qualitative text analysis (Hsieh and Shannon 2005) and combined coding, which combines elements of inductive and deductive coding (Hennink et al. 2011: 218-220; 220-225; Bazeley and Jackson, 2013: 76-106). The analysis was based on the example of Larsson and Holmström (2007), according to which transcripts were read several times to get an overall picture of the results. This was followed by the marking of the units of meaning from the data, which were based on the interview questions and showed different ways of understanding the researched concepts and different experiences of the interviewees. Subsequently, the different units of meaning were grouped on the basis of similarity and difference, and categories and sub-categories were created. The interview texts were coded several times, as new sub nodes emerged during the processing of the material, which in turn required a re-examination of the previous text, which is considered a normal process in qualitative data analysis (Hennink et al. 2011: 220; Mayring 2000). The sub-nodes were later grouped under the appropriate codes, and the names of the codes were specified. Both coders read and analyzed the transcripts, and as a result of joint discussions and preliminary summaries, a final analysis was made and written down, with the equal participation of both coders. According to Lewis and Ritche (2003, p. 271), internal reliability refers "to the extent to which assessments, judgments, ratings, and so on, internal to the research conduct, are agreed or replicated between researchers." During the research, there was close communication between the coders to agree on the coding. In the end, a consensus on the application of the same coding scheme was reached.

The results of the study were structured based on the theoretical framework of Valk (2014) discussed above (distribution of stakeholders, nature of collaboration with stakeholders, forms and principles of collaboration, factors influencing collaboration).

\section{Results}

In the classification of stakeholders, the authors first used the approach of Mitchell et al. (1997) and Clarkson (1995), which classifies stakeholders as primary (more important and more influential for the organization) and secondary (less important stakeholders). 
The stakeholders were mapped and prioritized, on the basis of which the main category 1-stakeholders of internal security education institutions and its sub-categories-primary stakeholders I and II and secondary stakeholders were formed (Table 2), after which the focus was moved only to primary stakeholders I. The main categories $2-4$, thus deal with the nature and forms of collaboration with the main stakeholders identified above, and the main category 5 deals with the factors influencing collaboration. The sub-categories and codes under categories $2-5$ are presented in Table 2.

\section{Category 1: Stakeholders of internal security education institutions}

Although the study participants identified a number of stakeholders, during a phenomenographic interview, they focused on those stakeholders considered to be the most important and who the interviewees were more involved with in practice. In the course of coding, the three most important or primary stakeholders were clearly distinguished, which were: (1) employers and their regional agencies, (2) the ministries under whose authority the interviewees work, (3) other higher education institutions (Sub-category 1.1, Table 2).

As students and other sub-categories of this stakeholder (alumni, applicants), employees and other ministries were referred to as important stakeholders on several occasions, and according to the interviewees, interaction with these took place on a regular basis, despite less talk of collaboration with these stakeholders, two sub-categories were established for primary stakeholders, the first containing stakeholders that had been most often referred to as the most important and that had essentially been focused on most during the interviews (primary stakeholders I), and the second containing stakeholders that were less referred to in terms of both frequency and content (primary stakeholders II). Furthermore, the least named and least referred stakeholders (society, other European level institutions, etc.) emerged as secondary stakeholders (Category I, Table 2).

The results show that institutions of professional higher education of internal security consider external stakeholders to be more important than internal ones, as only external stakeholders can be found in the first sub-category under the main stakeholders. As the aim of the study was to find out the forms of collaboration practiced with the main or primary stakeholders, the following four categories in Table 2 were formed on the basis of primary stakeholders I.

\section{Category 2: Collaboration with employers and their regional agencies}

Extensive collaboration with employers (e.g., the Police Board, police directorate, regional police departments, criminal police, the Rescue Board and its regional agencies, correctional agencies, etc.), as the most important stakeholder, takes place at several levels and, as a result of the study, can be divided into two: 1) Informal collaboration based on common interest, and 2) Formal collaboration.

Informal collaboration based on common interest

Networking

As a result of the survey, it became clear that in all professional higher education institutions, close Networking had developed between the higher education institution and the agencies in which other parties, such as representatives of the ministry, were also 
Table 2 Collaboration with stakeholders (compiled by the authors)

\begin{tabular}{|c|c|}
\hline Categories & Sub-categories and codes \\
\hline \multirow[t]{21}{*}{$\begin{array}{l}\text { Category 1: Stakeholders of Internal Security } \\
\text { Education Institutions }\end{array}$} & $\begin{array}{l}\text { Sub-category 1.1: Primary Stakeholders I } \\
\text { Codes: }\end{array}$ \\
\hline & 1.1.1 employers and their regional agencies \\
\hline & $\begin{array}{l}\text { 1.1.2 ministries under whose authority the interview- } \\
\text { ees work (Ministry of Interior/Ministry of Justice) }\end{array}$ \\
\hline & 1.1.3 other higher education institutions \\
\hline & $\begin{array}{l}\text { Sub-category 1.2: Primary Stakeholders II } \\
\text { Codes: }\end{array}$ \\
\hline & 1.2.1. students \\
\hline & 1.2.2. employees \\
\hline & 1.2.3. other ministries \\
\hline & 1.2.4. alumni \\
\hline & 1.2 .5 applicants \\
\hline & $\begin{array}{l}\text { Sub-category 1.3: Secondary Stakeholders } \\
\text { Codes: }\end{array}$ \\
\hline & 1.3.1 society \\
\hline & 1.3.2 other European level institutions \\
\hline & 1.3.4 trade unions \\
\hline & 1.3.5 secondary schools \\
\hline & 1.3.6 committees and councils \\
\hline & 1.3.7 press \\
\hline & 1.3.8 politicians \\
\hline & 1.3.9 other national training centers \\
\hline & 1.3.10 IT service centers \\
\hline & 1.3.11 local government institutions \\
\hline \multirow[t]{11}{*}{$\begin{array}{l}\text { Category 2: } \\
\text { Collaboration with Employers and Their Regional Agen- } \\
\text { cies }\end{array}$} & $\begin{array}{l}\text { Sub-category 2.1: Informal Collaboration Based on } \\
\text { Common Interest } \\
\text { Codes: }\end{array}$ \\
\hline & 2.1.1 Networking \\
\hline & 2.1.2 Personal contacts \\
\hline & 2.1.3 Joint marketing (reputation building) \\
\hline & $\begin{array}{l}\text { 2.1.4 The institution of professional higher education } \\
\text { as a mediator in specifying the needs of the interest } \\
\text { group }\end{array}$ \\
\hline & 2.1.5 Joint research and development \\
\hline & $\begin{array}{l}\text { Sub-category 2.2: Formal Collaboration } \\
\text { Codes: }\end{array}$ \\
\hline & 2.2.1 Regular meetings and visits \\
\hline & 2.2.2 Formal correspondence \\
\hline & 2.2.3 Formal networking \\
\hline & $\begin{array}{l}\text { 2.2.4 Feedback system } \\
\text { 2.2.5 Cooperation councils }\end{array}$ \\
\hline \multirow[t]{5}{*}{$\begin{array}{l}\text { Category 3: } \\
\text { Collaboration with Leading Ministries (Interior/Justice) }\end{array}$} & $\begin{array}{l}\text { Sub-category 3.1: Formal Cooperation Based on } \\
\text { Subordination } \\
\text { Codes: }\end{array}$ \\
\hline & 3.1.1. Stakeholder dominance and guidelines \\
\hline & 3.1.2 Trading \\
\hline & $\begin{array}{l}\text { Sub-category 3.2: Informal Collaboration } \\
\text { Code: }\end{array}$ \\
\hline & 3.2.1 Personal relationships \\
\hline
\end{tabular}


Table 2 (continued)

\begin{tabular}{ll}
\hline Categories & Sub-categories and codes \\
\hline Category 4: & Sub-category 4.1: Informal Collaboration Based on \\
Collaboration with Other Higher Education Institutions & Common Interest \\
& Codes: \\
& 4.1 .1 Competition and coping with it \\
& 4.1.2. Joint projects \\
& 4.1.3. Networking \\
& Sub-category 5.1: Factors Positively Affecting Col- \\
laboration & Codes: \\
& 5.1 .1 Common interest \\
Category 5: Factors Affecting Collaboration & 5.1 .2 Role of personality \\
& 5.1 .3 Organizational culture \\
5.1 .4 Involvement & 5.1 .5 Building trust \\
& Sub-category 5.2: Factors Negatively Affecting Col- \\
laboration & Codes: \\
5.2 .1 Conflict \\
5.2 .2 Competition \\
5.2 .3 Manipulation \\
5.2 .4 Strict hierarchy \\
5.2 .5 Domination \\
\end{tabular}

involved. The network includes specific partners with whom daily communication is held, whether by phone, face-to-face meetings, video conferences, or by e-mail. Communication is immediate, needs-based, and not regulated - if an issue needs to be resolved, the appropriate means will be chosen:

"I do cooperate with them weekly...they are developing the processes there, and it's a great chance to be part of that. It's not official; it's because we know each other, we keep calling each other, we keep meeting each other." (F1).

"What I have heard people say: I truly trust that network /.../." (F1).

\section{Personal contacts}

Collaboration with employers' offices and their regional agencies, as one of the most important stakeholders, is largely linked to people-to-people contacts, friendships, and trust, which means that collaboration in its true sense takes place informally and is always linked to specific people who the interviewees know personally, are accountable to and care for. Often, forms of collaboration based on partnership have also emerged because the interviewee has maintained good relations from a previous job in some office and has known the collaboration partners for years. The interviewees are used to communicating with each other regularly and sharing information; a kind of group of friends has formed:

"30 years I worked in the police department... that helps a lot. I have those connections from my previous life already and these build trust. I didn't leave, like slamming the doors." (G1). 


\section{Marketing (reputation building)}

Institutions of professional higher education and employers' agencies are well aware that their reputation is interlinked. For example, if the reputation of the police is high, the institution of professional higher education has applicants with a sufficiently high level and vice versa. In marketing, close informal communication takes place, influencing tools are also used; for example, messages are thought through in advance, communication principles are formulated, and so on.

In one professional higher education institution, three communication networks between the higher education institution and the employer agency had been established for this purpose: 1) network of communication managers, 2) internet network, and 3) social media network. Informal professional communication took place in all networks:

"For example, on the social media network - people there have a very strong interest in what is going on in social media, what is not working, they are a little bit nerdy ... you know what I mean. They are very determined, and they discuss, for example, what time we should post something on Facebook ... at 16:00 or 17:00 ... that is common for them." (N2).

\section{The institution of professional higher education as a mediator in specifying the needs of the stakeholder}

An interesting aspect emerged from the study in terms of the role of the mediator of the institution of professional higher education in specifying the needs of the stakeholders. Sometimes the employer agency is not able to describe its needs precisely, and therefore it is difficult to offer workable solutions; for example, police practitioners are not able to describe exactly to IT professionals in the private sector what platform or service they need, and here the institution of professional higher education can be of help. In the example of both Finland and Estonia, the institution of higher education has consciously taken up the task of specifying the needs when developing products or services.

"It depends on what kind of issue has to be solved. If it's like a new technology ... for police to use on a daily basis, a new platform or information exchange ... academics might be there to help find out what kinds of police services the police really need and then translate this understanding to industry, for SMEs who are delivering this platform. So, you can be a mediator." (F2).

The role of specifying the needs was also illustrated in the context of education services: the institution of professional higher education must set the employers' expectations for the quality of education, even if the agency cannot formulate its expectations precisely.

"If the employer itself cannot express what it wants in 6-7 years, but this information is important to us, then, of course, the role of the school is that we think about where the profession might develop. When an institution is ticking in its daily rhythm, we think about where society is moving, what is needed tomorrow ... this is actually the base that the school has to deal with." (E1). 
In both the Finnish and Estonian examples, special activities and methods (questionnaires, seminars, games, brainstorming, etc.) are used to specify the needs of different parties, with the help of which the expectations and interests of stakeholders are highlighted and formulated.

\section{Joint research and development}

Stakeholder involvement in R\&D projects takes place in various ways; for example, in Finland, project ideas are offered, employer agencies are introduced to opportunities to participate in joint projects as one party, joint research articles with agency experts are written, and presentations are made at seminars organized by the agencies. It is possible to involve the stakeholder group through a formal coordination system, which seeks to guide collaboration through official responsibility (appointment of a coordinator).

"If our stakeholder comes to us and wants some research that is important to them, we will communicate with them and, if necessary, participate in seminars organized by them. We also use articles - we ask stakeholders to write articles. More often, they ask us to write articles for their journals. Sometimes we write articles together. In the course of writing, we share ideas, exchange information, and have close cooperation with each other." (F2).

In conclusion, forms of collaboration based on partnership are characterized by keywords such as professionalism, mutual interest, practicality, reliability, supportive attitudes, and involvement.

\section{Formal collaboration}

As a rule, institutions of professional higher education are also hierarchically linked to employer agencies; that is, the institution of professional higher education, and the agencies are often subordinated to one ministry. Therefore, multi-level formal and regulated collaboration is commonly based on, for example, regular meetings and visits, formal correspondence, and networking.

As part of formal collaboration, a feedback system, which acts as part of the formal operational practices (G1, G0, G3) is described in detail: when the police officers finish school, they give feedback immediately, but also after years of working as a police officer, when they already have work experience. The police authorities with which the graduates work also provide feedback to the school on whether anything needs to be changed and whether the training meets contemporary requirements. There will be both oral feedback seminars and written interviews. The results are also sent to the school's academic staff, who receive information on whether the share of theoretical or practical work should be increased or decreased. Such a feedback system with the police authority as an employer was considered very important in the development of internal security education.

Formal communication also takes place in cooperation chambers and councils, as all professional higher education institutions have councils composed of representatives of stakeholders, where issues related to the school are discussed. The existence of the council is prescribed by law and is intended for the functioning of collaboration between the school and its stakeholders. In this form of cooperation, the conscious tactics of one 
higher education institution (Germany) stood out as especially interesting. As institutions of professional higher education usually have many stakeholders, the aim is to integrate stakeholders through the work of numerous collaboration chambers, instead of dealing with individual stakeholders:

"We tried to integrate them, and we have created a lot of councils actually ... they try to give us advice and recommendations. /.../ and we have integrated all these stakeholders together." (G1).

Communication in the councils is externally formal, but according to the interviewees (G1, E1, G0), it is highly meaningful. When disagreements or conflicts arise between different stakeholders, a smaller working group is formed, which develops solutions and then introduces them to a larger circle. The collaboration in the councils and committees was generally considered to be operational and successful.

Therefore, formal collaboration is primarily related to the formal structure and established by legislation.

\section{Category 3: Collaboration with leading ministries}

\section{Formal cooperation based on subordination}

The institutions of professional higher education in the field of internal security included in the sample operate under the Ministry of the Interior (Germany, Estonia), the Ministry of Justice and Public Security (Norway), and the Ministry of Education and Culture (Finland), and due to hierarchical power relations, collaboration is sometimes ambivalent. On the one hand, it is a dominant power relationship from the stakeholder's side, as the ministry is officially the owner of the school, forms the budget, supervises, and so on. The respondents described their subordination and dependence on the ministry in various ways, but of course, the inevitability of this hierarchy is understood.

"All the most important decisions are actually made in the ministry - how many students, how much money we get, human resources - how many lecturers we get.. In the ministries, the main decisions are made. We are not an independent university... we really depend on the ministry. Of course, we have little freedom in our organization. /.../ But the main decisions are made in /.../ the capital, in the ministry." (G2).

: ".../ they have their own logic of thinking ....../ You have to know that decisions in their organizations take time, .../.../. (F2).

The regulation of relations between the school and the employer agency was also pointed out as one of the power roles of the ministry:

"In practice, if the agency and the academy do not reach an agreement, the ministry will say what to do." (E1).

The coordinating role of the ministry in convening various thematic networks was also highlighted:

"The Ministry of Education gave us a task to build a systematic cooperation network... they sent this task to our university and they organized the first meeting. /.../ For the first two or three years it was not so effective, it took time to 
develop the cooperation model and when we discovered that it worked, we put more energy into it /.../ I received feedback from the Ministry that now I'm a real keyperson here."(F1).

Sometimes the ministry handles instructions for higher education the same way they handle ordinary agencies to which direct instructions can be given, although the school is an educational institution with its own rules about academic freedom:

"It happens because sometimes they see us as a police district. They forget that we are an academic institution /.../, for example, rapes.../.../, then they address us and ask: what do we know about rapes? And then they accuse us that you should know much more about rapes, there is too little research on rape, and so on. We say, yes, maybe it's true, there is too little research on rape but ... this is disrespect of our academic freedom ... they take us as a police district so they can give us orders... yes, this has sometimes been a point of conflict." (N1).

On the other hand, the ambivalent relationship with the ministry is described by the resource "trading out" tactics used by institutions of higher education from time to time:

"... The task of managers is to hammer out the best conditions for their institution; that is where it comes from. If there is a situation where a service is requested from us, but no money is given, then there are two options. The first is to resist, and the second is to go with the flow first and then start to steer the ship. In other words, to say that you understand that if the school does not receive funding, it means that after four years, there will be no qualified workforce../.../The transparency of the funds actually used here helps to show that we are not amassing it away to a safe somewhere, but that the money is invested in the future staff of the area of administration. In other words, there is a common interest; one needs to be cunning here." (E1).

The intensity of collaboration also largely depends on the specific officials in the ministry. For example, depending on the ministry's personnel policy, the collaboration will either intensify or subside, and the school will not be able to influence this too much.

\section{Informal collaboration}

Informal collaboration with the ministry was also clearly outlined. Several aspects could be highlighted. On the one hand, the substantive collaboration also requires informal communication, and if there is a need to communicate with the ministry on a daily basis, effective and mutually beneficial collaboration takes place. The collaboration is often good due to the fact that the people in the school have previously worked in the ministry, and this circle of acquaintances has remained and is put to good use in communication with the ministry.

"Before I started my work here, I was the head of the project and development unit. From that time, I know all these security actors in the ministry. Of course, they can't tell you everything, as I work in the academy now ... it's natural ... but we trust each other." (G2). 
"In general, ministries are considered high level /.../ I don't see them at such a high level because I am used to working with them /.../ I have to say that I have good contacts with the ministry, that's probably why I like dealing with them." (F2).

The results of the study also showed that the culture of collaboration is gradually shifting from dominance to partnership, and each other's competencies are respected and valued.

"Traditionally, the ministry has no people with an educational background. Of course, they have 2-3 people dealing with our college matters, and most of them have a law background. But they respect us, they ask for information and hear us." (N1).

In summary, it can be concluded that for the most part, the ministry is in a position of power in its collaboration with the school but depending on the situation and the precise individuals involved, institutions of professional higher education can also be equal partners with their experience.

\section{Category 4: Collaboration with other institutions of higher education Informal collaboration based on common interest Competition and coping with it}

The perception of other institutions of higher education was most diverse. The subjects understand the value of professional higher education but feel the need to introduce it more in society, as academic universities sometimes have a higher reputation. Universities were sometimes seen as dangerous stakeholders that could jeopardize the school's existence or with whom competition for resources takes place.

"We are competing for resources. Universities have a very high level of prestige ... we are not priority number one for most researchers, and that's why we want our police education to be more academic." (N1).

Institutions of professional higher education have also survived attacks by universities; for example, expert lecturers have headhunted away, a module at the institution of professional higher education is proposed to be transferred to the university, or a master's subject is taken away. Such events may (but may not) damage the relationship. However, efforts are made to get along peacefully and, if necessary, to collaborate with competitors.

"For example, 3-4 years ago, the government wanted to create a research group for radicalization. Our professor was an expert, and the university /.../ wanted him, and they took him from us. But we were very proud. He brought a lot of knowledge to them. He remained in contact with us, and we share knowledge. This did not spoil our relations. In the end, we want to have very strong knowledge in our police education. We want other universities also to have this knowledge." (N1).

\section{Joint projects}

Institutions of professional higher education can be stronger by acting together. First, it was found to be necessary to raise the reputation of professional higher education as a whole, to find common interests, joint advertising campaigns, and so on. Representatives of institutions of professional higher education expressed a conscious decision not 
to compete with other institutions of professional higher education, always trying to find opportunities for collaboration:

". is a small country, the stakeholders and academic people know each other. We stress the fact that the researchers should cooperate ... we want to inspire researchers..." (N1).

Relations with other universities were also felt to be enriching and important. All kinds of joint projects, joint modules, teacher exchanges, and so on are normal daily activities between higher education institutions.

"We have started master's education, we are dependent on cooperation with other universities, for example, with the law faculty of /.../ university." (N1).

\section{Networking}

Networking between higher education institutions is also common; for example, one Finnish interviewee was a professional creator and maintainer of a network and shared interesting information about his experiences in managing three networks. The first network consisted of representatives of institutions of professional higher education from all over the country; the second was intended to unite representatives of institutions of professional higher education and employers; the third was regional and included companies dealing with security issues, institutions of professional higher education, universities, vocational schools, and city government members. According to the interviewee, the creation of the network was a long process and took 2 to 3 years to become effective. He considered the basis of a functioning network to be: 1) the existence of a leader who initiates important discussions, finds important topics, 2) committed members, 3) trust between members that information remains confidential, and 4) regular communication.

"We keep seeing each other; we do have webinars, we do have Skype meetings, we meet on a regular basis." (F1).

In summary, the main keywords that described the collaboration with other universities are professional, seeking common ground, and practical.

\section{Category 5: Factors affecting collaboration}

The final category reflects the factors affecting collaboration. On the basis of the various descriptions examined, it can be pointed out that the existence of common interests and the credibility of the partners have a positive effect on collaboration. Collaboration is often positively influenced by the presence of a strong leader who, due to his/her personality, builds trust and a willingness to collaborate. In many ways, the manager of the organization, who also lays the foundation for the emergence of an organizational culture that promotes collaboration, is perceived as such a leader. Involvement is also important, as it shows the existence of interest and consideration for the other party.

Collaboration is negatively affected by competition, adherence to hierarchy, and the desire to dominate or manipulation the other partner and presents grounds for conflict.

As the topic of trust was shone through in several places, different interviewees also talked about building trust with stakeholders. A high level of professionalism was 
considered important: awareness of common interests, keeping promises, and a good experience of collaboration with the other party. Whether a relationship of trust has developed will only become clear after the end of the project. If the stakeholder returns with an interest in collaboration, it means that the previous project was successful, and the collaboration has been fruitful and based on trust.

"I would like to underline what beauty is in any cooperation with stakeholders. So, if you do good work, they come back to you ... then they contact and ask. Then I know I have done good work. That is a nice thing. Continuation of cooperation is a sign of success. This makes you try to do even better work with those who haven't come back." (F2).

When building a trusting and professional relationship with the authorities, it is very important to overcome the initial mistrust; for example, working police officers may not trust the people in an institution of professional higher education and may think that academics do not understand their daily work. In this case, they need to be made aware that academics can come up with workable solutions.

"They think that ok, we are academics ...we don't realize what the daily work is. So, the big thing from our side is to say that yes, we do know your daily work. Ok, we are not policemen ... but I am a crisis management expert, and now I work at the school, so yes, we have been on their side, and now we are on the academic side. Trust us because we really can understand what you really mean... we do know your daily life./.../" (F2).

Forms of collaboration are also influenced by the communication skills of specific people (including the top manager). Conscious use of communication skills helps the partnership to develop and deepen.

"The Rector is playing an active role there. The Rector is not part of the police, but she is doing very well in cooperation with police district chiefs. /.../ The Rector is very good with people. She has a very good memory; she remembers a child's birthday... she also started as a teacher of psychology. She is very well respected." (F1).

In summary, the main factors influencing collaboration are related to the existence of common interests and similar values. From there onward, it all depends on how trust can be built and maintained, and involvement, professionalism, and communication skills play a role here.

\section{Discussion}

The study showed that institutions of professional higher education in the field of internal security work closely with their main stakeholders. The interviewees mentioned employers, ministries to which they report, and other institutions of higher education as the main stakeholders (Fig. 1). Somewhat surprisingly, students who have been one of the most important stakeholders in the institution of higher education in previous studies (Mainardes et al. 2010; Chapleo and Simms 2010; Slabá, 2015) were not included among the first three stakeholders. This fact can be explained by the higher labor market orientation of the institution of professional higher education 


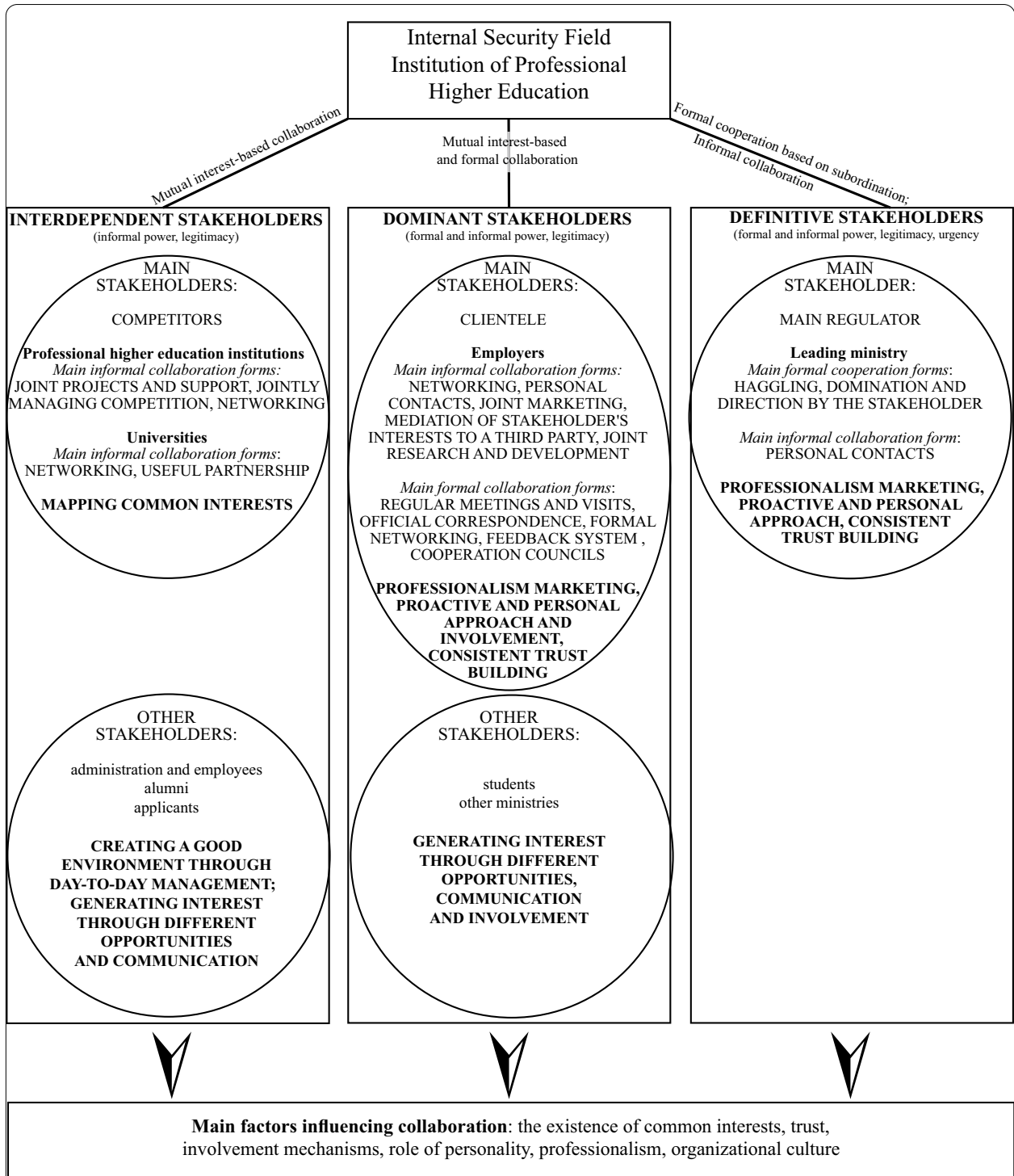

Fig. 1 Main stakeholders of institutions of higher education in internal security and the collaboration with them. Source: compiled by the authors after Valk (2014), Mitchell et al. (1997)

and academic freedom as a central value of traditional universities, which is why universities are not primarily oriented towards the interests of the world of work. One of the reasons why there are fewer collaboration practices related to students in the institutions of professional higher education is that collaboration with the employer (e.g., joint marketing activities) also indirectly affects the students as potential stakeholders. It is important for both the agency and the institution of higher education to attract good students, and collaboration with the employer agency also helps to serve this goal. Due to the specificity of institutions of professional higher education, the present study showed that they do not see other institutions of professional higher education as their competitors, but rather try to cope with the competition by supporting each other and sharing resources (lecturer exchange, joint marketing 
campaigns, etc.). Those universities that sometimes want to enter the landscape of professional higher education by taking over the curricula and students taught there are seen as a competitive threat.

As stakeholder classification models have been widely criticized (e.g., Mainardes et al. 2012; Neville and Menguc 2006; Parent and Deephouse 2007), as in Parent and Deephouse (2007), the descriptive framework proposed in this article seeks to achieve the goal that the stakeholder management model could be more limited in practice and would differentiate and focus on primary stakeholders. The study revealed that depending on who the institutions of professional higher education in the field of internal security consider being their main stakeholders, relations with the stakeholders are generally based on a common interest or on a formal basis and subordination (Fig. 1). Therefore, it can be said that Valk's (2014) general definition of collaborative relations, which was the basis of the study, corresponds to this by its nature (mutual interest-based collaboration partnership and continuous and periodic implementation partnership). By placing the results of the present study in the descriptive framework by Valk (2014), it was found that there were some differences between the results of the study and the output of the theoretical article. The authors consider this to be expected, given that even the creators of stakeholder theory acknowledge that the theory only guides the choice of possible variables and does not provide specific guidance (Wood et al. 2018).

While Valk (2014) categorized stakeholder relations into two (mutual interestsbased collaboration partnership and implementation partnership) and, based on this, differentiated (partly based on Mitchell et al. (1997)) the three main stakeholder categories (interdependent, dominant and definitive stakeholders), the results of the present study showed that, in the case of the two main stakeholders (agencies and ministry), which in the previous framework were under an implementation partnership, both types of relationship actually exist and that employer agencies value informal collaboration the most. All three main stakeholders that emerged from the present study are located in different stakeholder categories within the framework proposed by Valk (2014), so this classification of stakeholders was fully justified. In the framework proposed in this article, these stakeholders were named "main stakeholders," and the main forms of collaboration with them, and the main recommendations for collaboration have been indicated (Fig. 1).

Based on several authors discussed above, it was found that in the case of interdependent stakeholders, it is important to map mutual interests in order to find mutually beneficial places of collaboration. In the case of dominant and definitive stakeholders, professional skills should be marketed, and a more personal approach should be taken to build trust. In the case of dominant stakeholders, various inclusive activities are also very important, which help to involve the stakeholder more in the organization and maintain relations. In the case of both interdependent and dominant stakeholders, the framework also indicates "other stakeholders," who were mentioned by the interviewees as important, but with whom there are not so many substantive activities planned. It is important for these stakeholders to create a good environment through day-to-day management practices, opportunities, involvement, and communication (staff, students, applicants, alumni, other ministries). These 
dominant stakeholders include students and other ministries, which, due to their role, have both the formal and informal power to influence the organization, in contrast to interdependent stakeholders, which have rather informal power (Fig. 1).

As mentioned, relationships based on partnership and common interest are different from Valk's (2014) approach in all stakeholder categories, and this type of collaboration is most common with employers (Fig. 1), who are literally involved in almost all activities of the institution of higher education institution, from the creation of curricula and internships to the writing of research articles. There is also collaboration in reputation building and marketing activities, and the institution of professional higher education has taken on the role of an intermediary in the communication between the stakeholder and a possible third party, thus helping the stakeholder to specify its interests. Such close communication with the stakeholder certainly distinguishes institutions of professional higher education from traditional universities in past decades, and here we can draw a parallel with the proactive orientation discussed in the theoretical framework of the article (Narver et al. 2004; Casablanca 2015: 21; Buysse and Verbeke 2003; Sulkowski et al. 2018). Similar tendencies in connection with collaboration also emerged in communication with other institutions of higher education, where a lot of collaboration is done in building and valuing the reputation of professional higher education in society, and mutual support is provided. Activity and solving important issues in collaboration with many parties in different networks creates synergies and a variety of possible solutions, which once again shows the proactive approach and initiative of the participants. Proactive activity is also useful when the interest group (e.g., the employer agency) does not know its needs exactly, which emerged from the study and was also emphasized by Haaristo et al. (2015: 35-36). In this case, the institution of professional higher education can be a guide, ask questions, create connections, play through different solutions, and form an overall picture acceptable to the stakeholder. The partnership-based relationship with the governing ministry was manifested through personal contacts and was more related to the fact that some staff at the institution of higher education had previously worked in the ministry and keep former contacts fresh in the context of collaboration. On the one hand, this is certainly a good foundation for collaboration, and on the other hand, it may also help the ministry to develop an understanding of the differences between the culture of civil servants and the culture of academic freedom, and thus to take more account of the needs of the school.

Formal and hierarchical relationships were also considered necessary, and institutions of professional higher education have such relationships with employers and the ministry (Fig. 1). Among the forms of collaboration with employers, the conscious tactics used by one of the German universities for bringing together stakeholders through collaboration chambers stood out. The theory also emphasizes the need to combine thematic stakeholder management with a needs-based approach (Roloff 2008), and in this case, it is beneficial to all parties and saves valuable time. A formal relationship with the ministry is considered inevitable, as the ministry is officially the owner of the school and supervises it. However, the keyword "ambivalence" shines through in the attitude towards the academy, which is expressed in the fact that sometimes the ministry finds it difficult to understand the peculiarities of the educational institution, and the intensity of collaboration varies from period to period. In many 
ways, this has to do with the specific people who decide the most important issues. If there is a person in a position who does not value substantive collaboration, then it will not happen. As a rule, institutions of higher education have direct expectations and needs in regard to the ministry and, depending on the situation, proactively try to bring them to the table, as evidenced by the fact that institutions of higher education use tactics and persuasion to "trade out" resources in an ambivalent relationship.

An interesting outcome of the study was that the majority of institutions of higher education in the field of internal security and their interest groups are interested in informal collaboration. On the one hand, this is related to it being a special field where the average person does not often find themselves. Relationships are personal because people have been together for a long time and trust each other, and it may take a long time for a newcomer to adjust to the system. On the other hand, this tendency may also show certain danger signs, where the same people have been working for a long time in the structures important to the state, and who may no longer have a fresh, enthusiastic approach and this causes the environment to become stale. The question of how to keep employees committed becomes important. At the same time, collaboration can be one of the tools that make it possible to look at a slightly broader picture than one's organization; that is, as Gray (1989: 7) points out, good collaboration helps different parties look for solutions that go beyond their individual perspectives. The challenge here is to achieve a level of collaboration where interaction between the partners takes place, as Panitz (1996) has aptly observed. The fact that the relationships that institutions of higher education in the field of internal security have with stakeholders can be characterized by the concept of collaboration (and not just cooperation or coordination) is also shown by the fact that collaboration is related to "softer" characteristics such as trust, communication, knowledge, information sharing and transparency (Hogue 1993; Frey et al. 2006; Schöttle et al. 2014; Greer 2017: 132-133). On the one hand, this is surprising in a so-called masculine field; on the other hand, a strong feeling of your colleagues "having your back" and a sense of identity and common values are important to cope with a complex environment, as the internal security of the country ultimately depends on the functioning of the field and the collaborative skills of the people working there.

As a factor influencing collaboration, "soft topics" dominated, including the feeling of common interest, personal relationships, the skills of different key people, and the desire to collaborate (Fig. 1). The topic of relationships and trust was considered highly important, and often, for example, one's mistrust of the other party's knowledge or skills has to be overcome. This may occur in regard to practitioners and academics, where one party may feel that the other party is unfamiliar with the life and the other party is of the opinion that everything is done incorrectly. As mentioned above, it is possible to find places for collaboration here through more proactive activities: to be visible, to share one's experiences, to constantly learn, including being aware of what your partners are doing. Similar tendencies toward mistrust emerged in the studies by both Haaristo et al. (2015: 35-36) and Azman et al. (2018), whereas Williamson et al. (2016) also acknowledge that the key factors for a successful partnership are trust and mutual respect, which, according to their study, were associated with the largest number of other factors in the collaboration model. 
As with all studies, the present one has its limitations. One limitation is the number of interviewees. The authors proceeded on the basis of the assumption that in qualitative research, a suitable sample is one that provides adequate answers to the research questions (Marshall, 1996) and on the basis of the nature of phenomenographic research, which assumes that the phenomenon under study has as many properties as possible; that is, richness and thoroughness of descriptions (Thorne et al. 2009). Representatives of different countries participated in this study, and according to the authors, it contributed to obtaining diverse material with different nuances, which is also one of the aims of a phenomenographic study (Marton 1981; Barnard et al. 1999; Åkerlind 2005, 2008). The study used maximum variation sampling, in which each common pattern emerging from a large variability, as well as unique examples provided by individual cases, are values (Patton 2002: 234-235). Therefore, the authors consider that the sample was sufficient in this study. The use of different research methods can also be considered a limitation. At this point, the authors consider that in this study, it was justified in that all respondents were asked the same questions, and without exception, all interviews and the written qualitative survey were thorough and comparable in terms of content.

\section{Conclusion}

An analysis of the theoretical literature showed that stakeholder theory is, in fact, a diverse set of individually considered theories that offers many different perspectives without providing normative guidance on how to manage stakeholders in a particular organization or field. Various researchers have suggested that, in practice, the stakeholder model could be more limited and focus on key stakeholders. On the one hand, such an approach can help to focus activities better; on the other hand, it must also be borne in mind that the importance of interest groups may change over time, and at other times other interest groups may emerge and need attention. In other words, when creating stakeholder models, the limitations inherent in all models must be taken into account so you flexibly rearrange the activities if necessary. Despite the limitations, the models help to present and focus reality in a concentrated way. In order to find out the key stakeholders of institutions of higher education in the field of internal security and the nature of collaboration with them, the question was raised: Who are the main stakeholders of the institutions of professional higher education operating in the field of internal security, and what are the nature and main influencers of the cooperation with them? The authors aimed to identify the main stakeholders, the most important forms and practices of collaboration for institutions of professional higher education in the field of internal security in the four countries, as well as the factors that influence collaboration. While several studies of universities discussed in this article have found that students and internal stakeholders were considered to be the most important stakeholders, few studies of institutions of professional higher education have identified external stakeholders as dominant stakeholders, as confirmed by the study conducted in the framework of this article. It was also found that informal collaboration is most valued in terms of external stakeholders, and such relationships are best characterized by the concept of collaboration, which is inherently based on trust and soft values, which is surprising on the one hand in the field of internal security, and expected on the other. The study provided a comprehensive picture of the practice of collaboration in the selected institutions 
of higher education, and based on the research results, a descriptive framework was developed for classifying stakeholders of institutions of professional higher education in the field of internal security and explaining collaboration relationships. This then helped to understand the ambitions of the institutions of professional higher education in their management of stakeholders and provides basic recommendations for approaching different stakeholders. It also simplifies the overall picture of the stakeholder environment and allows attention to be paid to key aspects. According to the authors, further research could focus on the view stakeholders in this field have about collaboration and its forms, and the authors suggest focusing on the main stakeholders identified in the study.

Acknowledgements

Not applicable.

\section{Authors' contributions}

$\mathrm{AV}$ is the main author and was involved in planning the entire research process including the elaboration, categorization, and analysis of theoretical material, the preparation of a theoretical overview of the article, design of the empirical part, and the development of the interview questions. MK conducted and transcribed the interviews. AV and MK both read and analysed the transcripts, and as a result of joint discussions and preliminary summaries, a final analysis was made and written down, with the equal participation of both AV and MK. AV designed and wrote the article and coordinated it with the co-author. Both authors read and approved the final manuscript.

\section{Funding}

Not applicable.

\section{Availability of data and materials}

The participants in the study were guaranteed anonymity. The full transcripts created in the course of this study are not available to the public because they contain data that allows the participants to be identified. The data can be made available in a limited form (upon prior removal of the above information) from the responsible author upon reasonable request.

\section{Competing interests}

The authors declare that they have no competing interests.

Received: 9 June 2020 Accepted: 28 January 2021

Published online: 08 February 2021

\section{References}

Åkerlind GS (2005) Variation and commonality in phenomenographic research methods. H Ed Res \& Dev 24(4):321-334. https://doi.org/10.1080/07294360500284672

Åkerlind GS (2008) A phenomenographic approach to developing academics' understanding of the nature of teaching and learning. T in H Ed 13(6):633-644. https://doi.org/10.1080/13562510802452350

Alarcón-del-Amo MC, Casablancas-Segura C, Llonch J (2016) Responsive and proactive stakeholder orientation in public universities: antecedents and consequences. Higher Ed 72(2):131-151. https://doi.org/10.1007/s10734-015-9942-2

Arnold N, Ducate L, Kost C (2012) Collaboration or cooperation? Analyzing group dynamics and revision processes in wikis. CALICO J 29(3):431-448. https://doi.org/10.11139/cj.29.3.431-448

Azman N, Sirat M, Pang V, Lai YM, Govindasamy AR, Din WA (2018) Promoting University-Industry Collaboration in Malaysia: Stakeholders' Perspectives on Expectations and Impediments. J H Ed Pol and Man 41(10):1-18. https://doi. org/10.1080/1360080X.2018.1538546

Bazeley P, Jackson K (2013) Qualitative data analysis with NVIVO. Sage Publications Ltd, Thousand Oaks

Barnard A, McCosker H, Gerber R (1999) Phenomenography: a qualitative research approach for exploring understanding in health care. Qual Health Res 9(2):212-226. https://doi.org/10.1177/F104973299129121794

Beerkens M, Udam M (2017) Stakeholders in higher education quality assurance: Richness in diversity? H Ed Pol 30(3):341-359. https://doi.org/10.1057/s41307-016-0032-6

Bjørkquist C (2009) Stakeholder influence in higher education. old ideas in new bottles? Diss. Karlstad University Studies, Faculty of Social and Life Sciences

Bruneel J, D'Este P, Salter A (2010) Investigating the factors that diminish the barriers to university-industry collaboration. Res Pol 39(7):858-868. https://doi.org/10.1016/j.respol.2010.03.006

Buysse K, Verbeke A (2003) Proactive environmental strategies: a stakeholder management perspective. Strat Man J 24(5):453-470. https://doi.org/10.1002/smj.299

Caloghirou Y, Tsakanikas A, Vonortas NS (2001) University-industry cooperation in the context of the european framework programmes. J Tech Trans 26(1-2):153-161. https://doi.org/10.1023/A:1013025615518

Casablancas C (2015) strategic marketing and stakeholder orientation in the Spanish Public Universities: An Empirical Analysis Doctoral Thesis, University of Barcelona.

Cedefop (2017) VET at Higher Education levels. Understanding the National Policy Dimension: Country Case Studies. Dec 2017. Cedefop project 'Changing nature and role of vocational education and training in Europe'. Working 
paper 5. Available at: https://www.cedefop.europa.eu/files/working_paper_5_vet_at_higher_levels_count ry_case_studies.pdf

Chapleo C, Simms S (2010) Stakeholder identification \& prioritisation in the higher education sector: a case study of the University of Portsmouth. Persp 14(1):12-20. https://doi.org/10.1080/13603100903458034

Clarkson MBE (1995) A stakeholder framework for analyzing and evaluating corporate social performance. Acad of Man Rev 20(1):92-117

Conte R, Castelfranchi C (1996) Simulating multi-agent interdependencies a two-way approach to the micro-macro link. In: Troitzsch KG, Mueller U, Gilbert GN, Doran JE (eds) Social science microsimulation. Springer, Berlin, Heidelberg. https://doi.org/10.1007/978-3-662-03261-9_18

de Wit K, Verhoeven JC (2000) Stakeholders in universities and colleges in Flanders. Eur J of Ed 35(4):421-437. https:// doi.org/10.1111/1467-3435.00037

Deissinger T, Gonon P (2016) Stakeholders in the German and Swiss vocational education and training system: Their role in innovating apprenticeships against the background of academisation. Ed and $\operatorname{Tr}$ 58(6):568-577. https:// doi.org/10.1108/ET-02-2016-0034

Deissinger T (2015) The German dual vocational education and training system as 'good practice. Loc Econ 30(5):557-567. https://doi.org/10.1177/F0269094215589311

Deissinger T (2000) The German 'philosophy' of linking academic and work-based learning in higher education: the case of the 'vocational academies.'J of Voc Ed and Train 52(4):605-626. https://doi.org/10.1080/1363682000 0200134

Dekanoidze K, Khelashvili M (2018) Police education and training systems in the OSCE region. Ukrainian Ministry of Internal Affairs, Kyiv

European Union (2018) The European Qualifications Framework: supporting learning, work and cross-border mobility. Luxembourg: Publications Office of the European Union. doi:https://doi.org/10.2767/385613 http://www. ehea.info/Upload/TPG_A_QF_RO_MK_1_EQF_Brochure.pdf

Feltes T, Marquardt U, Schwarz S (2013) Policing in Germany: developments in the last 20 years. In: Meško G, Fields C, Lobnikar B, Sotlar A (eds) Handbook on policing in central and Eastern Europe. Springer, New York, NY. https:// doi.org/10.1007/978-1-4614-6720-5_7

Frey BB, Lohmeier JH, Lee SW, Tollefson N (2006) Measuring collaboration among grant partners. Am J of Eval 27(3):383-392. https://doi.org/10.1177/F1098214006290356

Freeman RE (2010) Strategic management: a stakeholder approach. Cambridge University Press, Cambridge

Freeman RE, Phillips R, Sisodia R (2018) Tensions in stakeholder theory. Bus \& Soc 59(2):213-231. https://doi. org/10.1177/0007650318773750

Friedman AL, Miles S (2002) Developing stakeholder theory. J Man Sts 39(1):1-21. https://doi. org/10.1111/1467-6486.00280

Gajda R (2004) Utilizing collaboration theory to evaluate strategic alliances. Am J Eval 25(1):65-77. https://doi. org/10.1177/F109821400402500105

Gray B (1989) Collaborating: finding common ground for multiparty problems. Jossey-Bass Publishers, San Francisco

Greer PA (2017) Elements of effective interorganizational collaboration: a mixed methods study. Diss. Antioch University

Goodpaster K (1991) Business ethics and stakeholder analysis. Bus Eths Q 1:53-73. https://doi.org/10.2307/3857592

Haaristo H-S, Kirss L, Mägi E, Rell M, Rozeik H (2015) Siseturvalisuse hariduse mudel. Poliitikauuringute Keskus Praxis, Tallinn

Hasnas J (1998) The normative theories of business ethics: a guide for the perplexed. Bus Eths Q 8:19-42. https://doi. org/10.2307/3857520

Hennink M, Hutter I, Bailey A (2011) Qualitative research methods. Sage Publications Ltd, Thousand Oaks

Hogue, T (1993) Community-based collaboration: community wellness multiplied. Oregon Center for Community Leadership, Oregon State University. Available at: http://crs.uvm.edu/nnco/collab/wellness.html. Accessed 1 Aug 2019

Hsieh H-F, Shannon SE (2005) Three approaches to qualitative content analysis. Qual Health Res 15(9):1277-1288. https://doi.org/10.1177/F1049732305276687

Jensen MC (2001) Value maximisation, stakeholder theory, and the corporate objective function. Eur Fin Man 7(3):297-317. https://doi.org/10.1111/1468-036X.00158

Kettunen J (2015) Stakeholder relationships in higher education. Ter Ed and Man 21(1):56-65. https://doi. org/10.1080/13583883.2014.997277

Key S (1999) Toward a new theory of the firm: a critique of stakeholder theory. Man Dec 37(4):317-328. https://doi. org/10.1108/00251749910269366

Larsson J, Holmström I (2007) Phenomenographic or phenomenological analysis: does it matter? Examples from a study on anaesthesiologists' work. Int J of Qual Sts Health Well-being 2(1):55-64. https://doi.org/10.1080/17482 620601068105

Lend E, Tamm J, Kõiv K, Ernits Ü, Kergand K Praun, J 2014 Rakenduskõrgharidus Euroopa kõrgharidusruumis: väljundid, institutsioonid ja toimemudelid 2020. Uuringu lõpparuanne. Eesti Rakenduskörgkoolide Rektorite Nõukogu. https://dspace.ut.ee/bitstream/handle/10062/45105/Rakenduskorgharidus_Euroopa_Korgharidusruum is.pdf? sequence $=1$ \&isAllowed $=y$

Levine JM, Moreland RL (2004) Collaboration: the social context of theory development. Pers and Soc Psyc Rev 8(2):164-172. https://doi.org/10.1207/s15327957pspr0802_10

Maguad BA (2018) Managing the system of higher education: competition or collaboration? Ed 138(3):229-238

Mainardes EM, Alves H, Raposo M (2012) A model for stakeholder classification and stakeholder relationships. Man Deci 50(10):1861-1879. https://doi.org/10.1108/00251741211279648

Mainardes EW, Alves H, Raposo M (2011) Stakeholder theory: issues to resolve. Man Dec 49(2):226-252. https://doi. org/10.1108/00251741111109133 
Mainardes EW, Alves H, Raposo M (2010) An exploratory research on the stakeholders of a university. J Man and Strat 1(1):76-88. https://doi.org/10.5430/jms.v1n1p76

Mampaey J, Huisman J (2015) Defensive stakeholder management in European universities: an institutional logics perspective. Sts in H Ed 41(12):2218-2231. https://doi.org/10.1080/03075079.2015.1029904

Marcoux A (2003) A fiduciary argument against stakeholder theory. Bus Eth Q 13:1-24. https://doi.org/10.5840/ beq20031313

Marić I (2013) Stakeholder analysis of higher education institutions. Interdisc Desc Comp Syst 11(2):217-226

Marshall MN (1996) Sampling for qualitative research. Fam Pract 13(6):522-526. https://doi.org/10.1093/fampr a/13.6.522

Marton F (1981) Phenomenography_describing conceptions of the world around us. Instr Sc 10(2):177-200. https:// doi.org/10.1007/BF00132516

Mayring P (2000) Qualitative content analysis. F: Qual Soc. https://doi.org/10.17169/fqs-1.2.1089

Ministry of the Interior Finland Homepage. Organisation chart. https://intermin.fi/documents/1410869/15717343/ englanninkielinen+hallinnonalan+organisaatiokaavio.pdf/4f961cb6-47c2-5526-050e-e7011c2fe93e/englannink ielinen+hallinnonalan+organisaatiokaavio.pdf?t=1599117547814

Mitchell RK, Agle BR, Wood DJ (1997) Toward a theory of stakeholder identification and salience: defining the principle of who and what really counts. Ac of Man Rev 22(4):853-886. https://doi.org/10.2307/259247

Melhuish L (2017) Dangerous liaisons: Exploring employer engagement relationships in vocational undergraduate adventure and outdoor management degrees. Ind and H Ed 31(1):3-10. https://doi.org/10.1177/0950422216 686474

Musial K (2010) Redefining external stakeholders in nordic higher education. T Ed and Man 16(1):45-60. https://doi. org/10.1080/13583881003629822

Narver JC, Slater SF, MacLachlan DL (2004) Responsive and proactive market orientation and new-product success. J Prod Innov Man 21(5):334-347. https://doi.org/10.1111/j.0737-6782.2004.00086.x

Neville BA, Menguc B (2006) Stakeholder multiplicity: toward an understanding of the interactions between stakeholders. J Bus Eth 66(4):377-391. https://doi.org/10.1007/s10551-006-0015-4

OECD (2018) Higher education in Norway: labour market relevance and outcomes. OECD Publishing, Paris

O'Leary R, Vij N (2012) Collaborative public management: where have we been and where are we going? Am Rev P Admin 42(5): 507-522. Doi: https://doi.org/10.1177/0275074012445780

Orts EW, Strudler A (2002) The ethical and environmental limits of stakeholder theory. Bus Eth Q 12(2):215-233. https ://doi.org/10.2307/3857811

Panitz T (1996) A Definition of Collaborative vs. Cooperative Learning. http://colccti.colfinder.org/sites/default/files /a_definition_of collaborative_vs_cooperative_learning.pdf. Accessed 31 July 2019

Parent MM, Deephouse DL (2007) A case study of stakeholder identification and priorization by managers. J Bus Eth 75(1):1-23. https://doi.org/10.1007/s10551-007-9533-y

Patton MG (2002) Qualitative Research \& Evaluation Methods, 3rd edn. Sage Publications, Thousand Oaks, London, New Dehli

Peterson NL (1991) Interagency collaboration under part h: the key to comprehensive, multidisciplinary, coordinated infant/toddler intervention services. J E Interv 15(1):89-105. https://doi.org/10.1177/105381519101500111

Podnar K, Jancic Z (2006) Towards a categorization of stakeholder groups: an empirical verification of a three-level model. J Mark Comms 12(4):297-308. https://doi.org/10.1080/13527260600720376

Lewis J, Ritche J (2003) Generalizing from qualitative research. In: Ritchie J, Lewis J (eds) Qualitative research practice: a guide for social science students and researchers. SAGE Publications, London

Roloff JJ (2008) Learning from multi-stakeholder networks: issue-focused stakeholder management. J Bus Eth 82(1):233-250. https://doi.org/10.1007/s10551-007-9573-3

Rowley TJ (1997) Moving beyond dyadic ties: a network theory of stakeholder influences. Acad Man Rev 22(4):887910. https://doi.org/10.2307/259248

Russo AP, van den Berg L, Lavanga M (2007) Toward a sustainable relationship between city and university a stakeholdership approach. J Plan Ed and Res 27(2):199-216. https://doi.org/10.1177/0739456X07307208

Sandelowski M (2000) Whatever happened to qualitative description? Res Nurs Health 23:334-340. https://doi. org/10.1002/1098-240X(200008)23:4\%3c334:.AID-NUR9\%3e3.0.CO;2-G

Schlierer H-J, Werner A, Signori S, Garriga E, VonWeltzien HH, VanRossem A, Fassin Y (2012) How do European SME owner-managers make sense of'stakeholder management'?: Insights from a cross-national study. J Bus Eth 109(1):39-51. https://doi.org/10.1007/s10551-012-1378-3

Schöttle A, Haghsheno S, Gehbauer F (2014) Defining cooperation and collaboration in the context of lean construction. In: Proceedings of the 22nd annual conference of the international group for lean construction, pp 1269-1280. Oslo Norway.

Seppo M, Roolaht T (2012) The policy suggestions concerning motivations and barriers of university-industry cooperation. Est Disc on Ec Pol 20(1):226-246. https://doi.org/10.15157/tpep.v20i1.783

Slabá M (2015) Stakeholder groups of public and private universities in the republic-identification, categorization, and prioritization. R Econ Persp 15(3):305-336. https://doi.org/10.1515/revecp-2015-0022

Sternberg E (1997) The defects of stakeholder theory. Corp Gov: An Int Rev 5(1):3-10. https://doi. org/10.1111/1467-8683.00034

Study in Finland homepage. https://www.studyinfinland.fi/universities-list-view?educational_level=University \%20of\%20Applied\%20Science\&level_of_degree=All\&field_of_study=All

Sulkowski AJ, Edwards M, Freeman RE (2018) Shake your stakeholder: firms leading engagement to cocreate sustainable value. Org Env 31(3):223-241. https://doi.org/10.1177/1086026617722129

Thorne S, Armstrong E-A, Harris SR, Hislop TG, Kim-Sing C, Oglov V, Oliffe JL, Stajduhar KI (2009) Patient real-time and 12-month retrospective perceptions of difficult communications in the cancer diagnostic period. Qual H Res 19(10):1383-1394. https://doi.org/10.1177/1049732309348382 
Ulicna D, Messerer KL, Auzinger M (2016) Study on Higher Vocational Education and Training in the EU, Final Report. Doi:10.2767/421741. file:///C:/Users/47101120286/Downloads/KE0416319ENN.en.pdf

Valk A (2014) Establishing and managing a network of stakeholders: a descriptive framework for collaboration between the institution of professional higher education and its stakeholders. J Man and Ch 32/33(1/2):89-108

Williamson HJ, Young B-R, Murray N, Burton DL, Lubotsky Levin B, Massey OT, Baldwin JA (2016) Community-university partnerships for research and practice: application of an interactive and contextual model of collaboration. $J$ H Ed Outr and Eng 20(2):55-84

Wood DJ, Mitchell RK, Agle BR, Bryan LM (2018) Stakeholder identification and salience after 20 years: progress, problems, and prospects. Bus \& Soc. https://doi.org/10.1177/0007650318816522

Yin RK (2011) Qualitative research from start to finish. The Guilford Press, New York

\section{Publisher's Note}

Springer Nature remains neutral with regard to jurisdictional claims in published maps and institutional affiliations.

Submit your manuscript to a SpringerOpen ${ }^{0}$ journal and benefit from:

- Convenient online submission

- Rigorous peer review

- Open access: articles freely available online

- High visibility within the field

- Retaining the copyright to your article

Submit your next manuscript at $>$ springeropen.com 